\title{
Basalt fibres as a sustainable reinforcement for cement based mortars: preliminary study
}

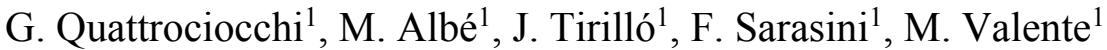 \\ \& M. L. Santarelli ${ }^{1,2}$ \\ ${ }^{1}$ Dipartimento di Ingegneria Chimica Materiali Ambiente, \\ Sapienza University, Italy \\ ${ }^{2}$ CISTEC - Centro di ricerca in scienza e tecnica per la conservazione \\ del patrimonio storico-architettonico, Italy
}

\begin{abstract}
Considering that uncontrolled construction and inappropriate choices of products are elements that consistently contribute to create a non-sustainable city, this work paid special attention to building science aiming at evaluating basalt fibre as a potential material for eco-compatible constructions. The microstructural and physico-mechanical properties of cement-based mortars reinforced with basalt fibres have been investigated through mechanical (compression and bending) as well as water absorption tests of the hardened materials. Two different mortars consisting of cement, the most common material on the construction market, plus siliceous aggregate were characterized using thermogravimetric analysis (TGA). The effect of basalt fibres with different morphologies at different contents on the mechanical behaviour of the resulting mortars was investigated. Fibre reinforced mortars showed an improvement in flexural and compressive strength compared to the neat mortars which was found to depend strongly on the type of matrix and content of fibres. In particular, relatively small fibres enhance the behaviour of mortars indicated for renewal and finishing uses. This can potentially lead to many applications of a natural and quite innovative material in ceramic matrices as a substitute to glass, carbon or polymeric fibres in building science.

Keywords: fibre reinforcement, mortar, basalt fibres, Portland-limestone cement, bending strength, compressive strength.
\end{abstract}




\section{Introduction}

Being "environment" the main focus of contemporary society efforts, each technological field needs to be as careful as possible in the search of a potential solution for the reduction of pollution and to ease the material recycle process, considering, at the same time, the availability of resources. As well known, this issue involves all the aspects of the material life-cycle from the production and application to its end. In the present study, considering that uncontrolled construction and inappropriate choices of materials may consistently contribute to create a non-sustainable city, special attention has been paid to the building science. Purpose of the present work is to improve the mechanical properties of materials frequently used in this ambit, such as hydraulic binders through the addition of environmentally friendly fibres. Amongst the wide selection of possible products, the binder chosen in this study is Portland limestone-cement, not only one of the most common types of cement on the market but also effective in the reduction of $\mathrm{CO}_{2}$ emissions during the production process in comparison with ordinary Portland cement. In fact, the primary sustainability effect is that less clinker has to be produced for an equivalent amount of cement, subsequently, the consumption of energy is reduced as well as $\mathrm{CO}_{2}$ or other greenhouse gases emissions $[1,2]$. The addition of fibres as reinforcement to cement is well known in literature, starting from e.g. asbestos and the related well-known problems linked to the safety [3, 4], leading to strength and toughness improvement depending on the characteristics of the fibre/matrix interface [5]. Currently, the fibre market is mainly divided between glass, steel and polyolefin fibres, especially polypropylene. Glass fibres are usually used in non-demanding applications due to the lower price of this product, in spite of a worse mechanical behaviour. Recent studies [6, 7] showed how the basalt fibre can find a new space in this specific market even though the studies on the use of basalt fibres are mainly limited to concrete based on type I Portland cement [810]. In addition, from the above review there is not enough investigation on the influence of basic parameters such as fibre content, fibre length and morphology on the properties of the resulting composites. Therefore the main aim of this investigation is to study the effect of the fundamental parameters, namely the fibre content and the morphology of basalt fibres on the mechanical behaviour of two cement-based mortars. The rationale behind the choice of basalt fibres lies in the fact that they not only respond to the needs of compatibility and sustainability of materials in the field of construction, being eco-compatible due to their mineral origin and absence of additives in the melting phase, but unlike the fibres with biological origin they do not show the same weakness in an alkaline environment as well as their natural degradation [11]. These fibres produced at high temperature from the melting of selected extrusive igneous rocks with a content of $45-52 \% \mathrm{SiO}_{2}$, as continuous filaments, earned the definition of "the green industrial material of $21^{\text {st }}$ century". Because the filaments have a diameter larger than 9 micron and are not subject to longitudinal fracture, the fibres should not be considered as inhalable [12]. 
Moreover, the process of separation between fibres and mortar at the end of product life-cycle is simplified by the very high melting point of basalt.

\section{Materials and methods}

\subsection{Mortars}

Two different mortars were prepared with two types of basalt fibres. The hydraulic binders chosen for the mortars were two different products of the most common Portland cement commercially used on the Italian market, namely Type II/b Portland limestone cement in accordance with European standard EN 197-1: 2011 [13], supplied by Buzzi (henceforth labelled as "PIIa") and by Italcementi (hereafter labelled as "PIIb"). PIIa is indicated as cement for structural uses while PIIb is described as cement for renewal applications. The ratio binder to aggregate was chosen as 1:2 (by weight) with siliceous feldspathic sand with a particle size range between $180-600 \mu \mathrm{m}$ as aggregate. The basalt fibres added to the matrix were supplied by Basaltex NV, and consist of (a) BSC D-L-WET, basalt continuous filament roving chopped (Ch.) to a length of $6.35 \mathrm{~mm}$, filament diameter in the range 10-19 $\mu \mathrm{m}$ and with a silane sizing; (b) MF01 milled (M.) basalt fibres obtained by milling basalt continuous filament fibres of the 10$17 \mu \mathrm{m}$ filament diameter range with a silane sizing. Basalt fibres were added at three different weight contents $(1 \%, 3 \%$ and $6 \%)$ while specimens of neat mortars were used as control (PIIa REF, PIIb REF). The workability and dispersion of fibres were preliminary assessed using different mixing parameters in order to determine the best working condition. Three mortar specimens of dimensions $160 \mathrm{~mm}$ x $40 \mathrm{~mm}$ x $40 \mathrm{~mm}$ were prepared per each composition in accordance with UNI EN 1015-11:2007 [14]. Fibres were considered as a part of the aggregate, therefore the ratio binder to aggregate remained constant. Table 1 summarizes the addition of water to the binder in order to ensure the best workability in presence of the fibres. Specimens of mortars were cured in water for 28 days as per UNI EN 196-1 2005 [15].

Table 1: Water/binder ratio as a function of different weight percentage and morphology of basalt fibres.

\begin{tabular}{|c|c|c|}
\hline $\begin{array}{c}\text { Content of basalt fibres } \\
(\mathrm{wt} \%)\end{array}$ & $\begin{array}{c}\text { Water/binder ratio for } \\
\text { milled fibres }\end{array}$ & $\begin{array}{c}\text { Water/binder ratio for } \\
\text { chopped fibres }\end{array}$ \\
\hline 1 & 0.43 & 0.45 \\
\hline 3 & 0.46 & 0.55 \\
\hline 6 & 0.50 & 0.70 \\
\hline
\end{tabular}




\subsection{Analysis of the raw materials}

The hydraulic binders were studied through thermogravimetric analysis (TGA) performed using a SDT Q600 (TA Instruments) with platinum crucibles at $10^{\circ} / \mathrm{min}$ heating rate in air flow $(50 \mathrm{ml} / \mathrm{min})$ from $30^{\circ} \mathrm{C}$ to $1000^{\circ} \mathrm{C}$.

The grain size of siliceous feldspathic aggregate analysed by mechanical sieving and its composition were reported elsewhere [16].

\subsection{Mechanical characterization}

The mechanical properties of the mortars were evaluated as per UNI EN 101511:2007 [17] using a Zwick/Roell Z010 universal testing machine equipped with a $10 \mathrm{kN}$ load cell. Three-point flexural tests were carried out on three specimens for each mixture with a support span of $120 \mathrm{~mm}$, a cross-head speed of $2 \mathrm{~mm} / \mathrm{min}$ and a pre-load of $5 \mathrm{~N}$. Young's modulus of the mortars was evaluated measuring the beam centre deflection thanks to a displacement transducer placed at the span centre. Cubic portions of each specimen resulting from the previous flexural test were used to carry out the compression strength test on an Instron 8033 with a cross-head speed of $2 \mathrm{~mm} / \mathrm{min}$.

\subsection{Water absorption measurement}

Water absorption was measured on one portion of each specimen resulting from the flexural tests in accordance with UNI 1015-18: 2004 [18]. Measurements were carried out on three specimens of dimensions $80 \mathrm{~mm}$ x $40 \mathrm{~mm}$ x $40 \mathrm{~mm}$ per each composition.

\subsection{Microstructural characterization}

Microstructural and morphological characterization of the fracture surfaces of the hardened specimens was performed by scanning electron microscopy (SEM) (SEM Philips XL40). All specimens were sputter coated with gold prior to examination.

\section{Results and discussion}

With regard to the raw materials, figure 1 shows the differences in composition between the two cements determined through TGA analysis. Weight loss and derivative curves show the main difference between the two binders in the range $670^{\circ} \mathrm{C}$ and $717^{\circ} \mathrm{C}$ in correspondence of the endothermic peak of $\mathrm{CaCO}_{3}$ decarbonation. The percentages of the weight losses for $\mathrm{CaSO}_{4}, \mathrm{Ca}(\mathrm{OH})_{2}$ and $\mathrm{CaCO}_{3}$ were evaluated and reported in table 2; as visible, PIIa was found to be richer in $\mathrm{CaCO}_{3}$ than PIIb. 


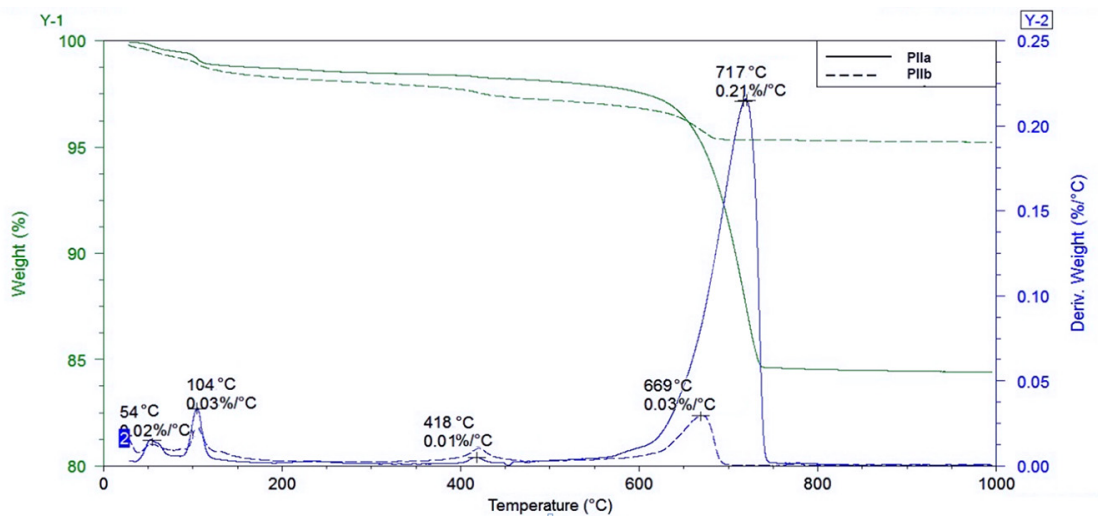

Figure 1: Weight loss and derivative curves obtained from the TGA analysis of the two cements.

Table 2: $\quad$ TGA data for the two Portland cements.

\begin{tabular}{|c|c|c|c|c|c|}
\hline \multirow{2}{*}{ Specimen } & $\mathrm{T}\left({ }^{\circ} \mathrm{C}\right)$ & $\begin{array}{c}\text { Weight } \\
\text { loss (\%) }\end{array}$ & $\begin{array}{c}\mathrm{CaSO}_{4} \\
(\mathrm{wt} \%)\end{array}$ & $\begin{array}{c}\mathrm{Ca}(\mathrm{OH})_{2} \\
(\mathrm{wt} \%)\end{array}$ & $\begin{array}{c}\mathrm{CaCO}_{3} \\
(\mathrm{wt} \%)\end{array}$ \\
\hline \multirow{3}{*}{ PIIa } & 110 & 0.03 & 0.06 & & \\
\cline { 2 - 6 } & 420 & 0.01 & & 0.04 & \\
\cline { 2 - 6 } & 717 & 0.21 & & & 0.70 \\
\hline \multirow{3}{*}{ PIIb } & 106 & 0.02 & 0.05 & & \\
\cline { 2 - 6 } & 420 & 0.01 & & 0.04 & 0.07 \\
\cline { 2 - 6 } & 670 & 0.03 & & & \\
\hline
\end{tabular}

Table 3 summarizes the mechanical properties as a function of mortar, type and content of basalt fibres. The results obtained express how the basalt fibres modify the mechanical properties in bending and compression of mortars based on cement binders. The effects are greatly different depending on the type of binder, the morphology and percentage in weight of the addition.

For what concerns the PIIa specimens, data show that the addition of basalt fibres caused a general decrease in the compressive and flexural strengths of the mortars.

In general, the addition of milled fibres to PIIa specimens leads to an increase of the flexural modulus at least at the lowest content, while causing the strength properties to decrease to a lesser extent compared to chopped fibres.

As regards PIIb specimens, the presence of milled fibres at the lower content, namely $1 \mathrm{wt} \%$, was found to highly increase the flexural strength of the neat mortar, also the other percentages exhibit an increase in comparison with the reference, but lower than the enhancement due to addition of $1 \%$. Addition of low percentage $(1 \mathrm{wt} \%)$ results in a good increase of the compressive strength. With regard to chopped fibres, their addition leads to an enhancement of flexural strength with no modification of the compressive strength for the low percentage 
( $1 \mathrm{wt} \%$ ). Addition of the most consistent amount of fibres, namely $6 \mathrm{wt} \%$, causes a slight decrease of the flexural strength associated to a marked decrease of compressive strength, indicating this as an excessive content.

Table 3: Mechanical properties of hardened mortars.

\begin{tabular}{|l|c|c|c|}
\hline Samples & $\begin{array}{l}\text { Compressive } \\
\text { strength } \sigma[\mathrm{MPa}]\end{array}$ & $\begin{array}{l}\text { Flexural strength } \\
\sigma[\mathrm{MPa}]\end{array}$ & $\begin{array}{l}\text { Flexural modulus } \\
\text { E }[\mathrm{MPa}]\end{array}$ \\
\hline PIIa (REF) & $25.60(1.95)$ & $6.61(0.46)$ & $3459(393.60)$ \\
\hline PIIa + M. 1\% & $17.93(1.57)$ & $5.39(0.65)$ & $3648.30(112.85)$ \\
\hline PIIa + M. 3\% & $10.20(0.53)$ & $3.64(0.33)$ & $2770.45(173.88)$ \\
\hline PIIa + M. 6\% & $12.34(2.73)$ & $3.64(0.14)$ & $2010(218.24)$ \\
\hline PIIa + Ch. 1\% & $19.07(2.54)$ & $5.20(0.35)$ & $2572.75(212.24)$ \\
\hline PIIa + Ch. 3\% & $11.86(1.86)$ & $3.85(0.48)$ & $1925.05(42.64)$ \\
\hline PIIa + Ch. 6\% & $5.36(0.93)$ & $2.15(0.54)$ & $564(32.75)$ \\
\hline PIIb (REF ) & $24.14(1.37)$ & $4.55(0.35)$ & $3362(16.32)$ \\
\hline PIIb + M. 1\% & $35.10(0.80)$ & $5.63(0.54)$ & $2913.67(303.32)$ \\
\hline PIIb + M. 3\% & $20.93(0.80)$ & $5.38(0.22)$ & $2101.33(275.50)$ \\
\hline PIIb + M. 6\% & $12.81(3.94)$ & $4.62(0.40)$ & $1998(263.46)$ \\
\hline PIIb + Ch. 1\% & $24.27(1.10)$ & $5.33(0.13)$ & $3438.5(246.78)$ \\
\hline PIIb + Ch. 3\% & $22.73(2.93)$ & $5.57(1.04)$ & $3218(161.22)$ \\
\hline PIIb + Ch. 6\% & $10.12(0.43)$ & $4.41(0.68)$ & $2260(173.26)$ \\
\hline
\end{tabular}

As is visible in figure 2, chopped fibre reinforced mortars are the only ones to show a significant post peak softening behaviour due to a toughening effect, while the ones reinforced with milled fibres show a brittle stress-strain curve. The toughness is enhanced when microcracks coalesce into macrocracks and large fibres such as the chopped ones are able to interfere with their propagation (figure 3).

In an overall view, milled fibre reinforced mortars exhibit more often improvements of strength with a low toughening effect, which can be partially ascribed to the dimension of the fibres. When relative small microfibers as milled ones are used as reinforcement, in case of microcracks formation, they can help in reducing their propagation acting as filler and creating bridges between the microcrack surfaces thus significantly enhancing the strength of the 

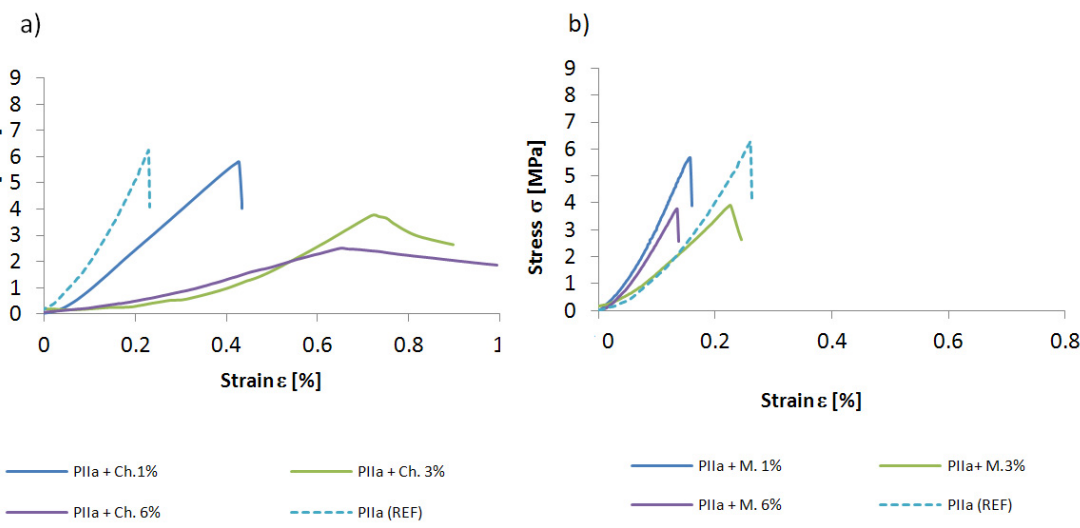

c)

d)
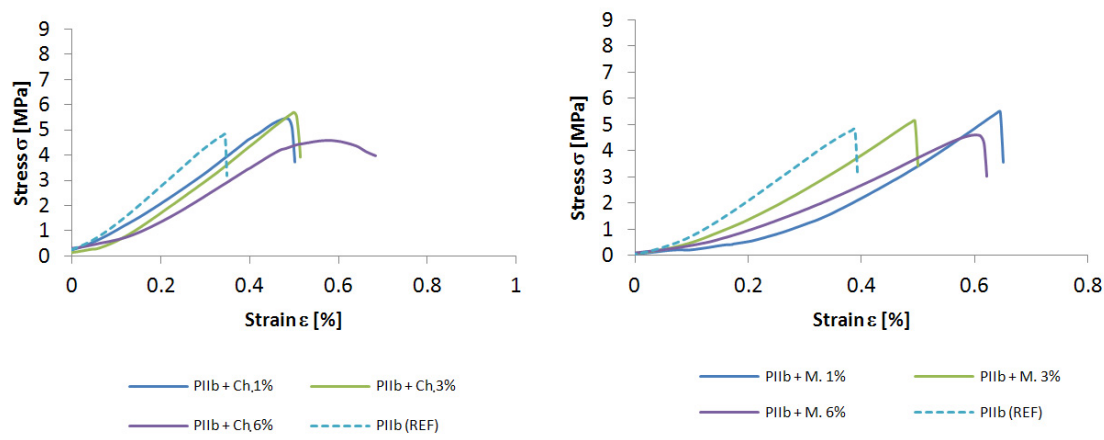

Figure 2: Typical flexural behaviour of PIIa mortars reinforced with (a) chopped and (b) milled basalt fibres; typical flexural behaviour of PIIb mortars reinforced with (c) chopped and (d) milled basalt fibres.

composite. This is more evident in case of PIIb specimens reinforced with milled fibres, which exhibit a better behaviour than chopped ones as for the flexural and compressive strength [19], but a lower toughening effect.

The decreasing trend related to the increase of content may depend on many factors; amongst them the difficulty of obtaining a homogeneous mixture in presence of the fibres, especially with regard to chopped morphology. Information on the distribution of the fibres in the matrices and on the fracture mechanisms was obtained through the morphological analysis of the specimen surfaces after flexural tests. 


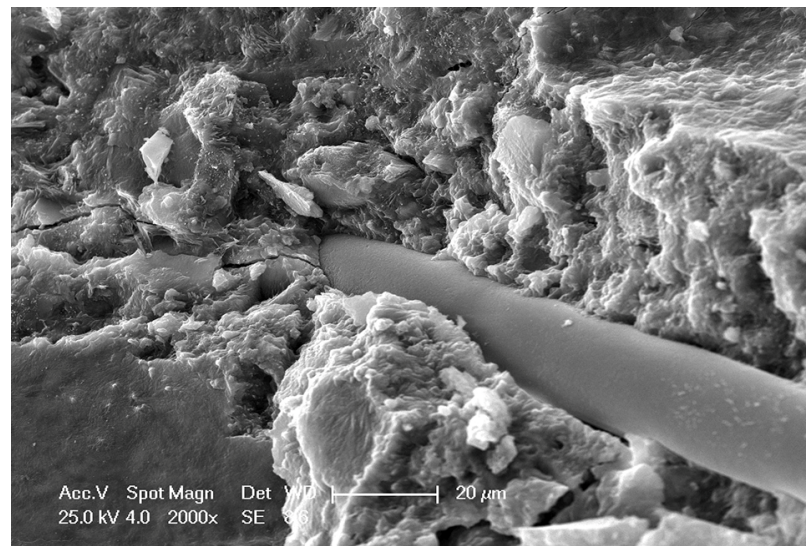

Figure 3: $\quad$ SEM micrograph of a sample of mortar containing PIIb and chopped fibre at $1 \mathrm{wt} \%$.

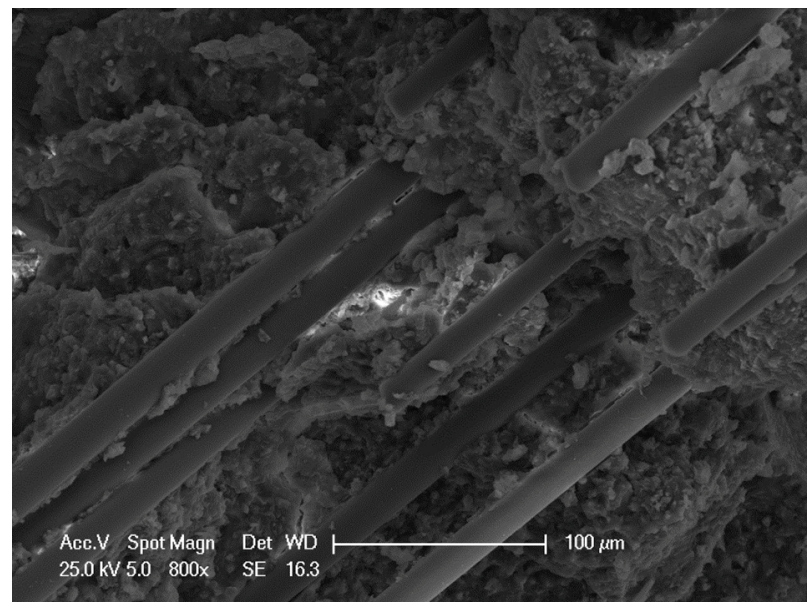

Figure 4: SEM micrograph showing a parallel group of chopped fibres from sample PIIa and chopped fibre at $3 \mathrm{wt} \%$.

In figure 4 is well visible how a group of chopped fibres constitutes a nondispersed cluster in the matrix. The dispersion of relatively large fibres is more difficult with increasing content in the mixture, their workability decreases requiring addition of water that can subsequently result in a potential increase of porosity (see table 1); thus, depending on the matrix, a threshold exists after which the addition of fibres does not reinforce or toughen the material [20]. Moreover, figure 5 shows how an increase of chopped fibre content causes an increase of capillary absorbed water. This increase in presence of chopped fibres is more noticeable in comparison with milled fibre reinforced mortars especially 
at $6 \mathrm{wt} \%$. Addition of fibres at $6 \%$ by weight, in fact, not only caused a decrease in the mechanical properties for both binders, but exhibited an increase in the amount of water absorbed by the mortar as per figure 5(a), (c).
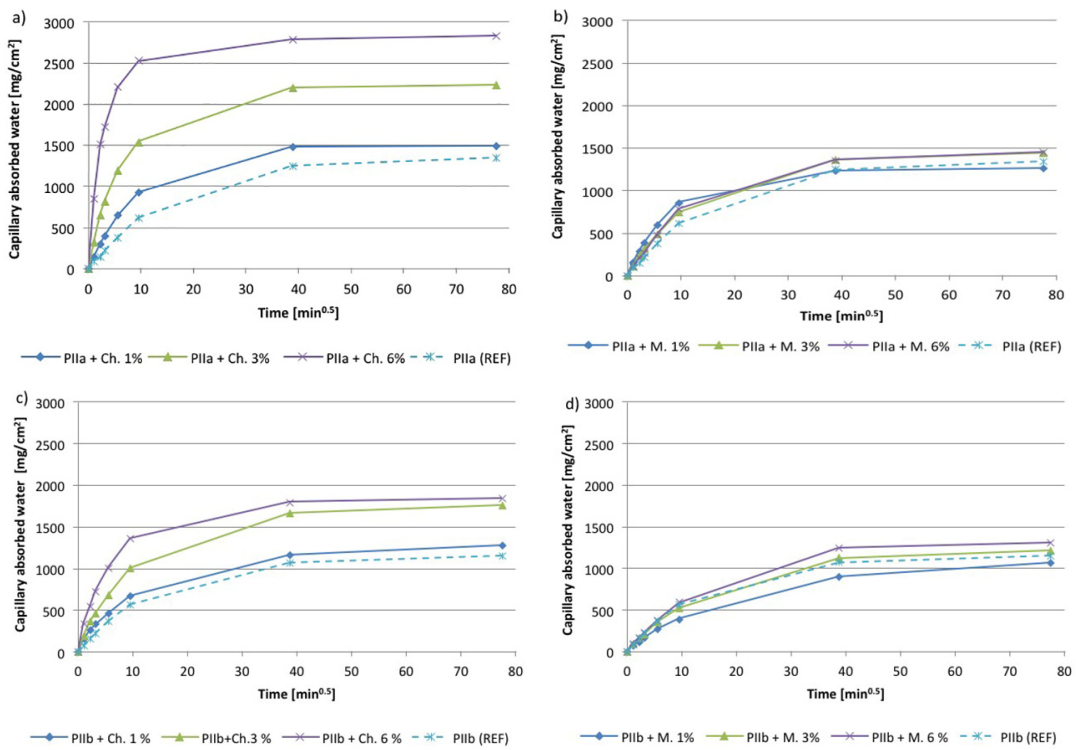

Figure 5: Water absorption of PIIa mortars reinforced with (a) chopped and (b) milled basalt fibres; water absorption of PIIb mortars reinforced with (c) chopped and (d) milled basalt fibres.

Decrease of mechanical properties may be caused by the increase of porosity due to the amount of water used to enhance the workability in presence of fibres, especially chopped ones at $6 \mathrm{wt} \%$.

Results from specimens containing PIIa show a more significant decrease in the mechanical properties with increasing basalt fibre contents compared to the samples based on PIIb matrix. This may be explained considering the composition of PIIa; as determined through TGA analysis, PIIa content of $\mathrm{CaCO}_{3}$ is higher than PIIb content, influencing the effective binder to aggregate ratio in favour of the latter one. The chemical reactivity of $\mathrm{CaCO}_{3}$ in Portlandlimestone cements has been a debated issue for many years; in fact, while previously it was believed to act only as inert filler, current researches show that limestone reacts but only to a limited extent [21]. As regards the specimens considered in this study, the behaviour of the two binders seems to be influenced by the amount of limestone as a dilution of the cement past.

In figure 6 it is visible how the Portland-limestone cement PIIb reacts at the interface with a chopped fibre causing a good adhesion of the reaction products to the surface; while in figure 4 the fibre surfaces are quite smooth, and a very small quantity of products from the hydraulic or areal reactions is visible. 


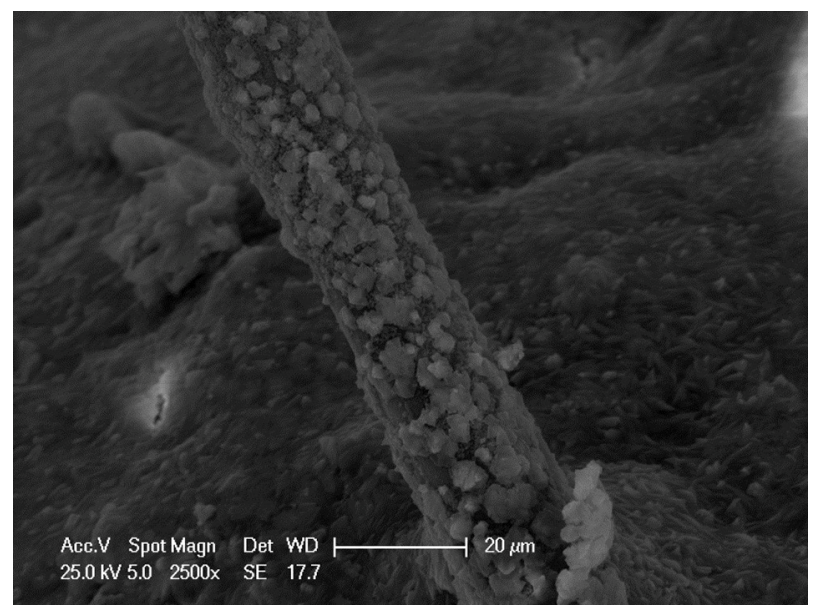

Figure 6: SEM micrograph of the reaction of Portland cement at the interface with a chopped fibre from PIIb and chopped fibre at $3 \mathrm{wt} \%$.

\section{Conclusions}

Two Portland-limestone cement based mortars were reinforced with two different types of basalt fibres at various percentages. The behaviour of the mortars was consistently modified by the addition of fibres, as determined by the bending and compression tests as well as comparing the capillary absorbed water. The conclusions can be summarized as follows:

- PIIb milled fibre reinforced specimens show a better compressive and flexural strength than the ones with addition of chopped fibres. Nonetheless, chopped fibres are effective in modifying the brittle characteristic of the reinforced mortars;

- For both types of fibres there is an optimum fibre content after which a decrease in the mechanical properties is visible as well as an increase in water absorption, being $1 \mathrm{wt} \%$ for PIIb matrix. In the case of PIIa matrix, no improvement in both flexural and compressive strength was observed. As a general comment, milled fibres exhibited the best combination of physicomechanical properties for both binders.

One of the main problems that emerged during the sample preparation is the homogeneous dispersion of fibres in the matrix; object of further investigation may be the optimization of a premix ready to be used on the worksite. Another important aspect to be considered in further studies is the role played by the interface in these Portland-limestone based composites. Especially in case of structural applications, to satisfy two opposing needs such as strength and toughness enhancement, the development of an optimized surface treatment for the fibres.is strongly needed. 
This study is to be considered a preliminary phase of a more complex work involving the comparison of the behaviour of several natural fibres in building science applications in order to obtain a material able to be not only ecosustainable but also competitive on the overall market of the fibres. Notwithstanding, it is already possible to see from the obtained results the efficiency of these fibres in the enhancement of mechanical properties in Portland-limestone cement-based composites used for renewal applications.

\section{References}

[1] Goguen C. Portland-Limestone Cement, Precast Magazine, May-June 2014. (Online)

[2] Hooton RD, Nokken M, Thomas MDA. Portland-Limestone Cement, State-of-the-Art Report and Gap Analysis for CSA A 3000, University of Toronto, 2007.

[3] Hannant DJ. Fibre reinforcement in the cement and concrete industry, Materials Science and Technology, 11, 853-862, 1995.

[4] European Council Directive of 19 September 1983 on the protection of workers from the risks related to exposure to asbestos at work (second individual Directive within the meaning of Article 8 of Directive 80/1107/EEC) (83/477/EEC).

[5] Ostertag CP, Yi C. Crack/fiber interaction and crack growth resistance behavior in microfiber reinforced mortar specimens, Materials and Structures, 40, 679-691, 2006.

[6] De Fazio P. Basalt fiber, from earth an ancient material for innovative and modern application, Energia, Ambiente e Innovazione, 3, 89-96, 2011.

[7] Sim J et al. Characteristics of basalt fiber as a strengthening material, Composites, Part B, 36, 504-512, 2005.

[8] Kabay N. Abrasion resistance and fracture energy of concretes with basalt fiber, Construction and Building Materials, 50, 95-101, 2014.

[9] Jiang C, Fan K, Wu F, Chen D. Experimental study on the mechanical properties and microstructure of chopped basalt fibre reinforced concrete, Materials and Design, 58, 187-193, 2014.

[10] Sinica M, Sezeman GA, Mikulskis D, Kligys M, Česnauskas V. Impact of complex additive consisting of continuous basalt fibres and $\mathrm{SiO}_{2}$ microdust on strength and heat resistance properties of autoclaved aerated concrete, Construction and Building Materials, 50,718-726, 2014.

[11] Tolêdo Filho R et al. Development of vegetable fibre-mortar composites of improved durability, Cement and Concrete Composites, 25, 185-96, 2003.

[12] Oberdörster G. Nanotoxixology, An Emerging Discipline Evolving from Studies of Ultrafine Particles, Environmental Health Perspectives, 1, 823$839,2005$.

[13] EN 197-1, Cement - Part 1, Composition, specifications and conformity criteria for common cements. 
[14] UNI EN 1015-11, 2007. Metodi di prova per malte per opere murarie Parte 11, Determinazione della resistenza a flessione e a compressione della malta indurita.

[15] UNI EN 196-1, 2005. Metodi di prova dei cementi - Parte 1, Determinazione delle resistenze meccaniche.

[16] Santarelli ML et al. Basalt fiber reinforced natural hydraulic lime mortars, A potential bio-based material for restoration, Materials and Design, 63, 398-406, 2014.

[17] UNI EN 1015-11, 2007. Metodi di prova per malte per opere murarie Parte 11, Determinazione della resistenza a flessione e a compressione della malta indurita.

[18] UNI EN 1015-18, 2004. Metodi di prova per malte per opere murarie Determinazione del coefficiente di assorbimento d'acqua per capillarità della malta indurita.

[19] Boghossian E, Wegner LD. Use of flax fibres to reduce plastic shrinkage cracking in concrete, Cement and Concrete Composites, 30, 929-937, 2008.

[20] Santarelli ML et al. Malte più performanti con le fibre di basalto, Compositi Magazine, 7-16, Settembre 2014.

[21] Hawkins P et al. The Use of Limestone in Portland Cement, A State-of-theArt Review, EB227, Portland Cement Association, Skokie, Illinois, USA, 2003. 